\title{
ТРАНСГРАНИЧНАЯ ПЕРЕДАЧА ИНФОРМАЦИИ, СОСТАВЛЯЮЩЕЙ КОММЕРЧЕСКУЮ ТАЙНУ: ПРОБЛЕМА ПРАВОВОЙ КВАЛИФИКАЦИИ
}

Аннотация: В статье рассматриваются вопросы законодательного регулирования передачи информации, составляющей коммерческую тайну, а также основания трансграничной передачи информации, составляющей коммерческую тайну. Автор анализирует место информации, составляющей коммерческую тайну, в системе российского права, её соотношение с объектами интеллектуальной собственности, в частности, с секретами производства (ноу-хау), а также исследует природу прав обладателя информации, составляющей коммерческую тайну, и их соотношение с исключительными правами на объекты интеллектуальной собственности. Автором рассматриваются вопросы правовой квалификачии договора о трансграничной передаче информации, составляющей коммерческую тайну, а также исследуется возможность осуществления трансграничной передачи информации, составляющей коммерческую тайну, на основании иных договоров: лицензионного договора, договора коммерческой концессии, договора об оказании информационных услуг. Автором вносится предложение по дополнению Федерального закона от 29.07.2004 № 98-Ф3 «О коммерческой тайне» положением, закрепляющим трансграничную передачу информации, составляющей коммерческую тайну.

Ключевые слова: коммерческая тайна, трансграничная передача, конфиденциальность, секрет производства, правовая квалификация, квази-исключительные права, договор трансграничной передачи, лицензионный договор, договор коммерческой концессии, трансграничная передача информации. DOI: 10.7256/1994-1471.2014.1.9649

$\mathrm{T}$ рансграничная передача информации, составляющей коммерческую тайну, осуществляется на практике при заключении договоров о создании совместных предприятий (договоров о совместной деятельности), сделок слияния и поглощения, договоров купли-продажи акций и активов, инвестиционных, девелоперских соглашений и т.д. Заключение данных договоров в большинстве случаев сопровождается заключением соглашений о передаче конфиденциальной информации (соглашений о конфиденциальности) ${ }^{1}$.

Несмотря на распространенность заключений соглашений о конфиденциальности между российскими и иностранными контрагентами, российское законодательство не регулирует вопросы трансграничной передачи информации, составляющей коммерческую тайну. В Законе о коммерческой тайне получили закрепление

См. Канашевский В.А. Соглашения о передаче конфиденциальной информации: вопросы коллизионного права // Законодательство. 2013. № 5. С. 10.

лишь вопросы передачи информации, составляющей коммерческую тайну, внутри государства. В соответствии с пунктом 6 статьи 3 Федерального закона «0 коммерческой тайне» от 29.07.2004 № 98-Ф3² (далее - Закон о коммерческой тайне) под передачей информации, составляющей коммерческую тайну, понимается передача информации, составляющей коммерческую тайну и зафиксированной на материальном носителе, ее обладателем контрагенту на основании договора в объеме и на условиях, которые предусмотрены договором, включая условие о принятии контрагентом установленных договором мер по охране ее конфиденциальности. Кроме того, согласно пп. 3 п. 3 ст. Закона «Об информации, информационных технологиях и о защите информации» обладатель информации, если иное не предусмотрено федеральными законами, вправе передавать информацию другим лицам по договору или на ином установленном законом основании.

Собрание законодательства РФ. 2004. № 32. Ст. 3283.

(C) Терехова Елена Викторовна

* Аспирант кафедры международного частного права, Московский государственный юридический университет имени О.Е. Кутафина (МГЮА) 
Таким образом, российское законодательство закрепляет, что единственным основанием для передачи информации, составляющей коммерческую тайну, является договор. Именно в этом договоре должны быть закреплены объем и условия использования информации, составляющей коммерческую тайну, а также обязательные для принятия меры по охране конфиденциальности информации, составляющей коммерческую тайну.

Между тем, вопрос о том, на основании какого договора информация, составляющая коммерческую тайну, может быть передана контрагенту, в том числе за пределы Российской Федерации, не решен.

Следует отметить, что в настоящее время в научной литературе вопрос трансграничной передачи информации, составляющей коммерческую тайну, а также договоров, на основании которых такая информация может передаваться, исследуется крайне редко.

Прежде чем рассмотреть вопрос о договорах передачи информации, составляющей коммерческую тайну, необходимо установить правовую квалификацию предмета такого договора - информации, составляющей коммерческую тайну.

Вопросы о том, какое место занимает институт коммерческой тайны в национальном законодательстве, является ли коммерческая тайна институтом вещного права или права интеллектуальной собственности, является нерешенным в настоящее время.

В иностранных государствах вопрос о месте коммерческой тайны в системе права решается по-разному. Так, в США и Великобритании коммерческая тайна относится к интеллектуальной собственности, в Германии данный вопрос однозначно не решен, в основном, информация, относящаяся к коммерческой тайне, охраняется с помощью общих предписаний по защите недобросовестной конкуренции ${ }^{3}$.

В Соглашении по торговым аспектам прав интеллектуальной собственности (ТРИПС) ${ }^{4}$ «закрытая информация» (раздел 7) прямо отнесена к категории «интеллектуальная собственность» (п. 2 ч. 1 ст. 1).

До введения в действие части четвертой ГК РФ вопрос соотношения информации, составляющей коммерческую тайну, и ноу-хау очень активно обсуждался в юридической литературе. Выделялось две диаметрально про-

См.: Шахназаров Б.А. Правовое регулирование отношений по трансграничной передаче прав на объекты промышленной собственности: Автореф. дисс. ... канд. юрид. наук. М., 2010. С. 129.

Собрание законодательства РФ. 2012. № 37 (приложение, ч. VI). С. 2818-2849. тивоположных позиции. Попондопуло В.Ф. Сергеев А.П. ${ }^{6}$ и Гаврилин Ю.В. ${ }^{7}$ относили информацию, составляющую коммерческую тайну, к объектам интеллектуальной собственности, поскольку данная информация может носить характер результата творчества и обладает всеми свойствами объекта интеллектуальной собственности.

Рассолов И.М. ${ }^{8}$, Зенин И.А. ${ }^{9}$ и Городов О.А. ${ }^{10}$, напротив, доказывали, что информация, составляющая коммерческую тайну, не является объектом исключительных прав, поскольку информация, составляющая коммерческую тайну, и ноу-хау различаются характером, объемом и основаниями возникновения на них прав, у режима коммерческой тайны есть множественный субъект, тогда как ноу-хау может включать свойство исключительности, и ноухау полностью не поглощается коммерческой тайной, так как его потенциальная ценность не связана с конкретным бизнесом.

В. Погуляев обращает внимание также на третий подход к данной проблеме в юридической литературе: в отношении ноу-хау действует лишь фактическая монополия его владельца, выражающаяся в возможности устанавливать режим доступа к сведениям, составляющим ноу-хау, и принимать в отношении них превентивные меры ${ }^{11}$.

Вступление в силу части четвертой Гражданского кодекса Российской Федерации ${ }^{12}$ (далее ГК РФ) не решило проблему соотношения информации, составляющей коммерческую тай-

Попондопуло В.Ф. Коммерческое (предпринимательское) право: Учебник. М.: Юристъ, 2005. С. 178-180.

6 См.: Сергеев А.П. Право интеллектуальной собственности в Российской Федерации. М.: Юристъ, 1999. C. 621 .

Гаврилин Ю.В.Понятие и правовая охрана коммерческой тайны в РФ (научно-практический комментарий к ч. 1 ст. 139 ГК РФ). [Электронный ресурс] // СПС «КонсультантПлюс».

8 Рассолов И.М. Коммерческая тайна в частном праве // Образование и право. 2012. № 12. С. 15.

9 Зенин И.А. Основы гражданского права России (конспект лекций для специалистов по праву интеллектуальной собственности). М., 1993. С. 208-215; Гражданское право: Учебник / Отв. ред. Е.А. Суханов. М., 1999. Т. 2. Полутом 1. С. 574-580.

10 Городов О.А. Интеллектуальная собственность: правовые аспекты коммерческого использования. СПб., 1999. С. 136; Городов О.А. Интеллектуальная собственность предпринимателя // Коммерческое право: Учебник. В 2 ч. / Под ред. В.Ф. Попондопуло, В.Ф. Яковлевой. 3-е изд., перераб. и доп. М.: Юристъ, 2004. Ч. 1. С. 285-295.

11 Погуляев В. Коммерческая тайна и ноу-хау // ЭЖЮрист. 2004. № 18. С 18.

12 Собрание законодательства РФ. 2006. № 52 (1 ч.). Ст. 5496. 
ну, и ноу-хау. Из содержания ст. 1465 ГК РФ (Секрет производства (ноу-хау) следует, что любая информация, в отношении которой введен режим конфиденциальности, относится к секретам производства. При разных названиях ст. 1465 ГК РФ «Секрет производства (ноу-хау)» и п. 2 ст. 3 Закона о коммерческой тайне «Информация, составляющая коммерческую тайну (секрет производства)» их содержание совпадает дословно. Таким образом, российский законодатель отождествляет понятия «секрет производства» и «информация, составляющая коммерческую тайну».

Следуя логике законодателя, информация, составляющая коммерческую тайну (секрет производства), относится к охраняемым результатам интеллектуальной деятельности и является в силу ст. 128 ГК РФ объектом гражданских прав.

Далее следует обратиться к вопросу о квалификации договора, на основании которого будет осуществляться трансграничная передача информации, составляющей коммерческую тайну.

Пронин К.В. указывает, что передача информации, составляющей коммерческую тайну, может осуществляться в рамках договора коммерческой концессии ${ }^{13}$, поскольку статья 1032 ГК РФ возлагает на пользователя договора коммерческой концессии обязанность не разглашать секреты производства правообладателя и другую полученную от правообладателя конфиденциальную коммерческую информацию.

Клишина А.А. отмечает, что передача коммерческой тайны технического характера на практике обычно происходит посредством заключения лицензионного договора ${ }^{14}$.

Канашевский В.А. обращает внимание на то, что в связи с внесенными изменениями в Закон о коммерческой тайне с целью приведения его положений в соответствие с требованиями ГК РФ о секретах производства (ст. 1465 ГК РФ), передача конфиденциальной информации должна соответствовать требованиям части четвертой ГК РФ о передаче секрета производства (ноу-хау). Это означает, что в рамках действующего законодательства передача конфиденциальной информации может осуществляться на основании лицензионного договора ${ }^{15}$.

\footnotetext{
13 См.: Пронин К.В. Указ. соч. С. 73.

14 Клишина А.А. Охрана коммерческой тайны в экономическом обороте : автореф. дис. ... канд. юрид. наук : 12.00.03. M., 2004. С. 11.

15 См. Канашевский В.А. Соглашения о передаче конфиденциальной информации: вопросы коллизионного права. С. 11.
}

Представляется, что конструкция лицензионного договора применима не в полной степени к отношениям по передаче информации, составляющей коммерческую тайну. Основная причина такого вывода состоит в том, что обладателю информации, составляющей коммерческую тайну, не принадлежат исключительные права в отношении такой информации в том значении, в котором они применяются к объектам интеллектуальной собственности.

Так, право использовать объекты интеллектуальной собственности исключительно, поскольку оно «путем прямого запрета в законе устраняет других лиц (всех, кроме тех, для кого закон предусмотрел изъятия) от возможности использовать эти интеллектуальные продукты, т.е. «исключает» для этих «других» такую возможность» и «признает его за другими лицами лишь в качестве правомочия, полученного вторичным обладателем или производного от права автора (исполнителя, изобретателя) или заявителя» ${ }^{16}$. В отличие от объектов интеллектуальной собственности информация, составляющая коммерческую тайну, как таковая не может монопольно принадлежать одному лицу. В отличие от механизма исключительных прав механизм коммерческой тайны связан не с самими сведениями как результатом интеллектуальной деятельности, а с конфиденциальностью этих сведений, которая устанавливает запрет не на использование сведений (как исключительные права), а на их получение без согласия правообладателя. Следовательно, контрагент, получивший информацию, составляющую коммерческую тайну, на законном основании, обладает теми же правами пользования и распоряжения такой информацией, что и её обладатель (при условии принятия мер по защите её конфиденциальности).

Дозорцев В.А. предлагает называть такие права квази-абсолютными или квази-исключительными, поскольку такие права не предоставляют абсолютного характера защиты правообладателя ${ }^{17}$.

Тем не менее, в настоящее время заключение лицензионного договора о передаче информации, составляющей коммерческую тайну, иностранному контрагенту ввиду того, что законодатель отождествляет коммерческую

\footnotetext{
16 Маковский А.Л. Исключительные права и концепция части четвертой Гражданского кодекса // Гражданское право современной России / Сост. О.М. Козырь и А.Л. Маковский. М.: Статут, 2008. С. 135.

17 См.: Дозорцев В.А. Интеллектуальные права: Понятие. Система. Задачи кодификации. Сборник статей. М.: Статут, 2005. С. 228.
} 
тайну и ноу-хау, является приемлемым для обладателя информации, составляющей коммерческую тайну, и контрагента.

Шахназаров Б.А. отмечает, что трансграничная передача информации, составляющей коммерческую тайну, осуществляется на основании договора о передаче прав на использование информации, составляющей коммерческую тайну. Такой договор в большинстве стран характеризуется как договор особого рода - sui generis, который не может быть отнесен ни к одному из известных видов гражданско-правовых договоров ${ }^{18}$. Данное мнение также поддерживает А. Акопян, указывающий, что договоры об отчуждении коммерческой тайны и секретов производства (ноу-хау) являются договорами особого рода ${ }^{19}$. Следует полагать, что данное правило применимо и к России, и трансграничное соглашение о передаче информации, составляющей коммерческую тайну, не должно отождествляться с лицензионным договором.

Обращает на себя внимание мнение специалистов, которые указывают, что на основании договоров о передаче информации, составляющей коммерческую тайну, во многих случаях передается не столько сама информация, сколько оказываются информационные услуги, связанные с поиском, подбором, систематизацией и передачей нужной потребителю информации ${ }^{20}$. В отличие от договора об отчуждении исключительного права на секрет производства и лицензионного договора о предоставлении права использования секрета производства, по договору об оказании информационных услуг никаких исключительных прав на результаты интеллектуальной деятельности не передается ${ }^{21}$. По гражданско-правовому договору об оказании информационных услуг может передаваться любая информация, не ограниченная и не изъятая из оборота ${ }^{22}$. Такой договор может заключаться

18 См.: Шахназаров Б.А. Проблемы правового регулирования охраны секрета производства (ноу-хау) и его трансграничной передачи // Актуальные проблемы российского права. 2009. № 3. С. 524.

19 Акопян А. Правовая природа договора о передаче ноу-хау и его соотношение с другими гражданско-правовыми договорами // Право и экономика. 2006. № 12. C. 69-70.

20 См.: Алексеева Д.Г., Пыхтин С.В., Фальковская Я.М. Комментарий к Федеральному закону «О кредитных историях» (постатейный). М., 2006. С. 88-95.

21 Зверева Е. Договоры о передаче информации, составляющей коммерческую тайну (секрет производства) // Право и экономика. 2007. № 5. С. 42.

22 См.: Сайкина Т.И. К вопросу о гражданско-правовом регулировании безвозмездного оказания услуг // Законодательство. 2006. № 5. С. 78-84. между любыми субъектами права, в том числе в сфере предпринимательской деятельности, и часто именуется договором на информационное обеспечение и обслуживание ${ }^{23}$. Такие договоры квалифицируются как договоры возмездного оказания информационных услуг (ст. 779 ГК РФ) ${ }^{24}$.

Думается, что в рамках действующего законодательства трансграничная передача информации, составляющей коммерческую тайну, должна осуществляться на основании договора о трансграничной передаче информации, составляющей коммерческую тайну, лицензионного договора, договора коммерческой концессии либо договора об оказании информационных услуг. Такие договоры должны содержать условия о порядке использования информации, составляющей коммерческую тайну, мерах конфиденциальности, которые необходимо принять лицу, получающему право использовать информацию, составляющую коммерческую тайну, территорию и срок использования.

Представляется, что в Законе о коммерческой тайне следует закрепить положения о возможности трансграничной передачи информации, составляющей коммерческую тайну, и заключения договора о трансграничной передаче прав на информацию, составляющую коммерческую тайну.

Следует дополнить статью 3 Закона о коммерческой тайне следующим положением: «6.1. трансграничная передача информации, составляющей коммерческую тайну, - передача информации, составляющей коммерческую тайну, и зафиксированной на материальном носителе, ее обладателем иностранному контрагенту на основании договора в объеме и на условиях, которые предусмотрены договором, включая условие о принятии иностранным контрагентом установленных договором мер по охране ее конфиденциальности».
23 См.: Пугинский Б.И. Коммерческое право России. M., 2002. C. 230-232.

24 См.: Андреев Ю. Гражданско-правовые договоры возмездного оказания услуг (глава 39 ГК РФ) // Хозяйство и право. 2006. № 1. С. 119-128. 


\section{Библиография:}

1. Акопян А. Правовая природа договора о передаче ноу-хау и его соотношение с другими гражданско-правовыми договорами // Право и экономика. - 2006. - № 12. - С. 69-70.

2. Алексеева Д.Г., Пыхтин С.В., Фальковская Я.М. Комментарий к Федеральному закону «О кредитных историях» (постатейный). - М., 2006.

3. Андреев Ю. Гражданско-правовые договоры возмездного оказания услуг (глава 39 ГК РФ) // Хозяйство и право. - 2006. - № 1. - С. 119-128.

4. Гаврилин Ю.В. Понятие и правовая охрана коммерческой тайны в РФ (научно-практический комментарий к ч. 1 ст. 139 ГК РФ). [Электронный ресурс]. СПС «КонсультантПлюс».

5. Городов О.А. Интеллектуальная собственность: правовые аспекты коммерческого использования. - СПб., 1999.

6. Городов О.А. Интеллектуальная собственность предпринимателя // Коммерческое право: Учебник. В 2 ч. / Под ред. В.Ф. Попондопуло, В.Ф. Яковлевой. 3-е изд., перераб. и доп. - М.: Юристъ, 2004. Ч. 1.

7. Гражданское право / Отв. ред. Е.А. Суханов. - М., 1999. Т. 2. Полутом 1.

8. Дозорцев В.А. Интеллектуальные права: Понятие. Система. Задачи кодификации. Сборник статей. М.: Статут, 2005.

9. Зверева Е. Договоры о передаче информации, составляющей коммерческую тайну (секрет производства) // Право и экономика. - 2007. - № 5.

10. Зенин И.А. Основы гражданского права России (конспект лекций для специалистов по праву интеллектуальной собственности). - М., 1993.

11. Канашевский В.А. Соглашения о передаче конфиденциальной информации: вопросы коллизионного права // Законодательство. - 2013. - № 5.

12. Клишина А.А. Охрана коммерческой тайны в экономическом обороте : автореф. дисс. ... канд. юрид. наук : 12.00.03. - М., 2004.

13. Маковский А.Л. Исключительные права и концепция части четвертой Гражданского кодекса // Гражданское право современной России / Сост. О.М. Козырь и А.Л. Маковский. - М.: Статут, 2008.

14. Погуляев В. Коммерческая тайна и ноу-хау // ЭЖ-Юрист. - 2004. - № 18. - С 18.

15. Попондопуло В.Ф. Коммерческое (предпринимательское) право. - М.: Юристъ, 2005.

16. Пугинский Б.И. Коммерческое право России. - М., 2002.

17. Рассолов И.М. Коммерческая тайна в частном праве // Образование и право. - 2012. - № 12 .

18. Сайкина Т.И. К вопросу о гражданско-правовом регулировании безвозмездного оказания услуг // Законодательство. - 2006. - № 5. - С. 78-84.

19. Сергеев А.П. Право интеллектуальной собственности в Российской Федерации. - М.: Юристъ, 1999.

20. Шахназаров Б.А. Правовое регулирование отношений по трансграничной передаче прав на объекты промышленной собственности: Автореф. дисс. ... канд. юрид. наук. - М., 2010.

21. Шахназаров Б.А. Проблемы правового регулирования охраны секрета производства (ноу-хау) и его трансграничной передачи // Актуальные проблемы российского права. - 2009. - № 3.

\section{References}

1. Akopyan A. Pravovaya priroda dogovora o peredache nou-khau i ego sootnoshenie $s$ drugimi grazhdansko-pravovymi dogovorami // Pravo i ekonomika. - 2006. - № 12. - S. 69-70.

2. Alekseeva D.G., Pykhtin S.V., Fal'kovskaya Ya.M. Kommentarii k Federal'nomu zakonu «O kreditnykh istoriyakh» (postateinyi). - M., 2006.

3. Andreev Yu. Grazhdansko-pravovye dogovory vozmezdnogo okazaniya uslug (glava 39 GK RF) // Khozyaistvo i pravo. - 2006. - № 1. - S. 119-128.

4. Gavrilin Yu.V. Ponyatie i pravovaya okhrana kommercheskoi tainy v RF (nauchno-prakticheskii kommentarii k ch. 1 st. 139 GK RF). [Elektronnyi resurs]. SPS «Konsul'tantPlyus».

5. Gorodov O.A. Intellektual'naya sobstvennost': pravovye aspekty kommercheskogo ispol'zovaniya. SPb., 1999.

6. Gorodov O.A. Intellektual'naya sobstvennost' predprinimatelya // Kommercheskoe pravo: Uchebnik. V 2 ch. / Pod red. V.F. Popondopulo, V.F. Yakovlevoi. 3-e izd., pererab. i dop. - M.: Yurist”, 2004. Ch. 1.

7. Grazhdanskoe pravo / Otv. red. E.A. Sukhanov. - M., 1999. T. 2. Polutom 1.

8. Dozortsev V.A. Intellektual'nye prava: Ponyatie. Sistema. Zadachi kodifikatsii. Sbornik statei. M.: Statut, 2005. 
9. Zvereva E. Dogovory o peredache informatsii, sostavlyayushchei kommercheskuyu tainu (sekret proizvodstva) // Pravo i ekonomika. - 2007. - № 5.

10. Zenin I.A. Osnovy grazhdanskogo prava Rossii (konspekt lektsii dlya spetsialistov po pravu intellektual'noi sobstvennosti). - M., 1993.

11. Kanashevskii V.A. Soglasheniya o peredache konfidentsial'noi informatsii: voprosy kollizionnogo prava // Zakonodatel'stvo. - 2013. - № 5.

12. Klishina A.A. Okhrana kommercheskoi tainy v ekonomicheskom oborote : avtoref. diss. ... kand. yurid. nauk : 12.00.03. - M., 2004.

13. Makovskii A.L. Isklyuchitel'nye prava i kontseptsiya chasti chetvertoi Grazhdanskogo kodeksa // Grazhdanskoe pravo sovremennoi Rossii / Sost. O.M. Kozyr' i A.L. Makovskii. - M.: Statut, 2008.

14. Pogulyaev V. Kommercheskaya taina i nou-khau // EZh-Yurist. - 2004. - № 18. - S 18.

15. Popondopulo V.F. Kommercheskoe (predprinimatel'skoe) pravo. - M.: Yurist", 2005.

16. Puginskii B.I. Kommercheskoe pravo Rossii. - M., 2002.

17. Rassolov I.M. Kommercheskaya taina v chastnom prave // Obrazovanie i pravo. - 2012. - № 12.

18. Saikina T.I. K voprosu o grazhdansko-pravovom regulirovanii bezvozmezdnogo okazaniya uslug// Zakonodatel'stvo. - 2006. - № 5. - S. 78-84.

19. Sergeev A.P. Pravo intellektual'noi sobstvennosti v Rossiiskoi Federatsii. - M.: Yurist”, 1999.

20. Shakhnazarov B.A. Pravovoe regulirovanie otnoshenii po transgranichnoi peredache prav na ob"ekty promyshlennoi sobstvennosti: Avtoref. diss. ... kand. yurid. nauk. - M., 2010.

21. Shakhnazarov B.A. Problemy pravovogo regulirovaniya okhrany sekreta proizvodstva (nou-khau) i ego transgranichnoi peredachi // Aktual'nye problemy rossiiskogo prava. - 2009. - № 3.

Материал поступил в редакцию 21 сентября 2013 г. 